\title{
Inheritance and Quantitative Trait Loci Analysis of Resistance Genes to Bruchid and Bean Bug in Mungbean (Vigna radiata L. Wilczek)
}

\author{
Myon-Gi Hong ${ }^{1 \dagger}$, Kil-Hyun Kim ${ }^{2 \dagger}$, Ja-Hwan Ku², Jin-Kyo Jeong ${ }^{2}$, Min-Jung Seo ${ }^{2}$, Chang-Hwan Park ${ }^{2}$, Yul-Ho Kim³, \\ Hong-Sik Kim, Yong-Kwon Kim, So-Hyeon Baek, Dool-Yi Kim', Su-Kwon Park ${ }^{6}$, Sun-Lim Kim, Jung-Kyung Moon** \\ ${ }^{1}$ Animal and Plant Quarantine Agency, Anyang, 380-757, Rep. of Korea \\ ${ }^{2}$ National Institute of Crop Science, RDA, Suwon, 441-857, Rep. of Korea \\ ${ }^{3}$ National Institute of Crop Science, RDA, Pyeongchang, 232-955, Rep. of Korea \\ ${ }^{4}$ Rural Development Administration, Jeonju, 560-500, Rep. of Korea \\ ${ }^{5}$ Shingyeong University, Hwasung, 445-741, Republic of Korea \\ ${ }^{6}$ National Institute of Crop Science, RDA, Wanju, 565-238, Rep. of Korea
}

\begin{abstract}
Bruchid (Callosobruchus chinenesis L.) and pod sucking bug (Riptortus clavatus Thunberg) are serious insect pests during the reproduction stage and seed storage period of legume crops worldwide. However, few sources of resistance to each of these insects have been identified and characterized, and no genetic studies have been carried out with simultaneous tests of these two insects. In this study, the inheritance of seed resistance to Callosobruchus chinenesis L. and Riptortus clavatus Thunberg was examined in a mungbean cultivar, Jangan mungbean, which was developed by backcrossing with the V2709 resistant donor. The $F_{1}, F_{2}$, and $F_{3}$ seed generations were developed from the cross between susceptible and resistant parents, and evaluated for resistance to the two insects. It was found that resistance to bruchid and bean bug was controlled by a single dominant gene in the $F_{1}$ and $F_{2}$ seeds. However, the segregation pattern of reciprocal reaction to each insect in $\mathrm{F}_{2}$ seeds showed seeds were susceptible to each insect. These results suggest that the resistance genes in Jangan mungbean to bug and weevil are either different or closely linked with each other. A genetic linkage map $13.7 \mathrm{cM}$ in length with 6 markers was successfully constructed. Two QTLs were identified for bruchid resistance, and a QTL for bean bug resistance was detected. One of the QTLs for resistance to bruchid was shared with the QTL for bean bug. These newly developed closely linked markers will be used for cloning of the resistance genes to bruchid and bean bug in the future.
\end{abstract}

Keywords Mungbean, Insect resistance, Inheritance, QTL

\section{INTRODUCTION}

Mungbean (Vigna radiata L. Wilczek) is one of the most important legume crops in many Asian countries. It is widely grown in tropical and sub-tropical regions as a monoculture and as a component double-cropping system. It ranks $3^{\text {rd }}$ or $4^{\text {th }}$ in importance of legume crops, and is commonly consumed as bean sprouts in Asian countries. The major insect pests attacking mungbean include bruchid (Coleopterous: Bruchidae), pod borer (Lepidoptera: Pyralidae) and pod-sucking bug (Heteroptea: Alydidae). Bruchid, in particular, brings the most serious damage during storage, while pod-sucking bug damages plants, young pods, and seeds in field conditions.

Post-harvest damage to the seeds of mungbean, caused by a group of insect pests of the genus Callosobruchus (Coleoptera: Bruchidae), particularly C. chinensis L. and C. maculates F. is quite serious. This insect group is often referred to as bean weevils, or bruchids (Southgate 1979). Kang et al. (2003) reported that about 20 species of pod-sucking bugs caused damage to young pods of legume crops such as soybean (Glycine max L. Merill), mungbean

Received March 26, 2015; Revised March 29, 2015; Accepted March 29, 2015; Published March 31, 2015

*Corresponding author Jung-Kyung Moon, moonjk2@korea.kr, Tel: +82-63-238-5321, Fax: +82-63-238-5305

${ }^{+}$These authors contributed equally to this work. 
and cowpea ( $V$. unguiculata $\mathrm{L}$.) from flowering time to the pod ripening period. These bugs suck pods, developing seeds and ripened seeds through the reproductive stage. Among them, bean bug (Riptortus clavatus Thunberg) brings the most serious damage to soybean in the southwestern region of Japan (Ishimoto 1993).

Sources of resistance have been found in wild relatives and landraces of mungbean. In the wild species, TC1966 was first reported as a resistance resource by Fujii et al. (1989), while V2709 and V2802, as resistant landraces, were selected from over 1,000 AVRDC mungbean accessions by Talekar and Lin $(1981,1992)$. In an additional screening of 600 accessions of AVRDC's mungbean collection in 2004, only V2709BG and V2802BG were confirmed to confer complete resistance to $C$. chinensis and C. maculatus. These resistance resources have been used to breed commercial varieties in many countries. In Korea, Jangan mungbean was developed in 1999 as a new resistant cultivar by the backcrossing breeding method with V2709 as the resistant donor parent.

An accession (TC1966) of the wild species $V$. radiate var. sublobata, collected in Madagascar, has been identified to possess bruchid resistance controlled by a single dominant gene, $B r$ (Kitamura et al. 1988; Fujii et al. 1989). Ishimoto et al. (1996) suggested that the $B r$ gene should control not only bruchid resistance, but also bean bug resistance. In the landrace accession resistance study, both V2709BG and V2802BG were found to contain the same gene, displaying control of resistance by a single dominant gene with modifier effects (Somta et al. 2007). V2709 is a landrace which originated in India. Jangan mungbean was the first variety created by backcross breeding using V2709 as a resistance source, released in 1999. It displayed complete resistance to $C$. chinensis (damage of $0 \%$ in this study).

Genetic mapping of the bruchid resistance gene has been reported with molecular markers such as RAPD, RFLP and STS (Kaga and Ishimoto 1998; Young et al. 1992; Yang 1994). However, these results were obtained by phenotyping data, treated as a qualitative approach.

The present study aimed not only to identify the mode of inheritance of resistance to $C$. chinensis and $R$. clavatus in Jangan mungbean, but also to develop molecular markers surrounding the resistance genes by the QTL approach.

\section{MATERIAL AND METHODS}

\section{Plant material and DNA extraction}

Seeds of the mungbean cultivars Sunhwa mungbean, Jangan mungbean and a wild relative, TC1966, were used in the assay for resistance to bruchid and bean bug. Sunhwa mungbean is a susceptible cultivar, while Jangan mungbean and TC1966 are the genotypes with resistance to bruchid and bean bug. $F_{1}$ and $F_{2}$ individuals were generated in 2005 and 2006 from two crosses with $\mathrm{S} \times \mathrm{R}$ and $\mathrm{R} \times \mathrm{R}$ combinations. The $\mathrm{F}_{2}$ population of 460 individuals, derived from cross between Sunhwa and Jangan mungbean, was used for map construction. The DNA of these $F_{2}$ individuals was extracted by the method presented in Lambridge et al. (2000).

\section{Bioassay of bruchid and bean bug}

Newly emerged bruchid adults maintained on susceptible mungbean seeds were used for infestation of the seeds. For test of the parents, $F_{1}, F_{2}$, and $F_{2: 3}$ generations, twenty newly emerged bruchid adults were placed into Petri dishes with 5 to 50 seeds $10 \mathrm{~cm}$ in diameter and $2 \mathrm{~cm}$ high. Seven days after infestation (DAI), all bruchid adults were removed, and every seed was checked to ensure the presence of more than two eggs. The Petri dishes were then maintained in the growth chamber at $28^{\circ} \mathrm{C}$ and $70 \% \mathrm{RH}$. The number of damaged seeds was counted and recorded at 40 DAI.

In the bioassay test with bean bug, 2 nymphs of the $1^{\text {st }}$ instar stage were introduced into small Petri dishes $(5 \mathrm{~cm}$ in diameter and $1.5 \mathrm{~cm}$ high) containing one seed. Each Petri dish contained a cotton swab with distilled water. The seed and cotton swab in each Petri dish were isolated with a small wooden stick to prevent induction of germination or seed rot. After infestation, the Petri dishes were maintained in the growth chamber at $25^{\circ} \mathrm{C}$ and $60 \mathrm{RH}$ on $14 \mathrm{~L}$ : $10 \mathrm{D}$. The number of instar stage nymphs in each Petri dish was counted at one or two day intervals. 


\section{Screening of polymorphic SSR and STS markers}

A total of 118 SSR markers and 4 nucleotide sequences of resistance-specific proteins deposited at NCBI were screened in the susceptible and resistant parents for polymorphism test. The SSR primers were kindly provided by Dr. Park (Gwag et al. 2006). For the detection of polymorphisms in the 4 resistance-specific proteins (AB041817, AB041818, AB041819, and AB041820), general primers were designed for the simultaneous amplification of 4 sequences from the resistance-specific proteins (Table 1).

\section{Bulked segregant analysis for RAPD selection}

Bulked segregant analysis (BSA) was performed to identity RAPD markers potentially linked to the gene conferring resistance to bruchid and bean bug (Michelmore et al. 1991). The resistant bulk was created by pooling the DNA of 12 resistant individuals from the $114 \mathrm{~F}_{2}$ mapping population. Similarly, the susceptible bulk was formed with the DNA of 11 susceptible individuals. The resistant and susceptible DNA bulks and DNA from the two parents and two references (TC1966 as R type and Keumseong mungbean as $\mathrm{S}$ type) were screened with RAPD markers to identify appropriate markers. A total of 190 RAPD primers were used, 20 of which were selected from a previous report (Kaga et al. 1998). The remaining 170 RAPD primers were purchased from OPERON Inc. (CA, USA). Approximately $10 \mathrm{ng}$ of DNA was used as a template in a $20 \mu \mathrm{L}$ PCR reaction, which consisted of $2 \mu \mathrm{L}$ of reaction buffer containing $1.5 \mathrm{mM} \mathrm{MgCl} 2$ (Biotools, Korea), 0.8 $\mathrm{mM}$ dNTPs (Bioneer, Korea), $0.05 \mathrm{U} / \mu \mathrm{L}$ Taq polymerase (Biotools, Korea), $0.5 \mu \mathrm{M}$ primers and $0.4 \mu \mathrm{L}$ of DMSO. PCR was carried out at $94^{\circ} \mathrm{C}$ for $5 \mathrm{~min}$, followed by 5 cycles of $94^{\circ} \mathrm{C}$ for $30 \mathrm{sec}, 35^{\circ} \mathrm{C}$ for $5 \mathrm{sec}$, and $72^{\circ} \mathrm{C} 1 \mathrm{~min}$, which was linked to the second program of 35 cycles of $94^{\circ} \mathrm{C}$ for $15 \mathrm{sec}, 40^{\circ} \mathrm{C}$ for $45 \mathrm{sec}, 72^{\circ} \mathrm{C}$ for $1 \mathrm{~min}$ and a final extension at $72^{\circ} \mathrm{C}$ for $10 \mathrm{~min}$. Random primers that showed polymorphisms between the resistant and susceptible bulks were further analyzed in the $100 \mathrm{~F}_{2}$ individuals.

\section{CAP analysis}

The RAPD fragments highly correlated with insect resistance were cloned into the pDrive coning vector using a QIAGEN PCR Cloning kit (QIAGEN Inc.). The inserts of each clone were then sequenced using an ABI373 DNA Sequencer. Primer sets were designed using the Primer 3

Table 1. Primer list of SSR, STS, RAPD, and CAPs markers used in this study.

\begin{tabular}{cllc}
\hline \hline Marker & & Primer sequence $\left(5^{\prime}\right.$ to $\left.3^{\prime}\right)$ & Expected Size (bp) \\
\hline \multirow{2}{*}{ MB87 } & Forward & TCCCTTGTGGGAGATCCT & 293 \\
& Reverse & CTTTGCCACACTCCTTGC & \\
RP & Forward & ATGGAGTTCAGTGCCTTGC & $896-1391$ \\
BAXA99 & Reverse & CACACAATCCAGAAATGCCTTA & \\
OPB10 & - & AGGGTGCGTATA & \\
OPU06 & - & CTGCTGGGAC & \\
CBAXA99 & - & ACCTTTGCGG & \\
& - & AGACCCAGAG & \\
COPU11 & Forward & GCGGTCAGCACAGAATTTACTCATTT & \\
& Forward & CAGCACACTAACGATACATTTGACACG & 781 \\
COPU06 & Reverse & GACCCAGAGTCAAAGAGCAGTAACACC & \\
& Forward & CCTTTGCGGCATTTTGAAGGT & 542 \\
COPB10 & Reverse & TGCGGTTCCTATCAGCGTTCA & \\
& Forward & CTGGGACGTAAGCTATGGTGCAG & 970 \\
\hline
\end{tabular}


program (Rozen and Skaletsky 2000) (Table 1). The amplification reaction consisted of $50 \mathrm{ng}$ of genomic DNA, 5 pmoles of each forward and reverse primer, $200 \mu \mathrm{M}$ of each dNTP, $1.5 \mathrm{mM} \mathrm{MgCl}_{2}, 1 \mathrm{X}$ reaction buffer $910 \mathrm{mM}$ Tirs- $\mathrm{HCl}(\mathrm{pH} 8.3) 50 \mathrm{mM} \mathrm{KCl})$, and $1 \mathrm{U}$ of Taq DNA polymerase (Biotools, Korea) in a total volume of $50 \mu$ l. The reaction mixture was denatured at $94^{\circ} \mathrm{C}$ for $4 \mathrm{~min}$ and subjected to 35 cycles of $94^{\circ} \mathrm{C}$ for $30 \mathrm{sec}$, annealing at 50 $65^{\circ} \mathrm{C}$ for $30 \mathrm{sec}$, and $72^{\circ} \mathrm{C}$ for $1 \mathrm{~min}$, with a final extension at $72^{\circ} \mathrm{C}$ for $10 \mathrm{~min}$. The products amplified from the two parental DNAs were digested with different restriction enzymes for determination of the polymorphism within the insert. The identified CAPs were then tested for all $460 \mathrm{~F}_{2}$ individuals.

\section{QTL analysis}

A genetic linkage map by CAPs, SSR, and STS markers for the $F_{2}$ population, consisting of 460 individuals, was constructed using Mapmaker version 3 (Lander et al. 1987). QTLs were analyzed by single factor ANOVA and composite interval mapping (CIM). Single factor ANOVA analysis was performed in SAS (SAS institute Inc.), while CIM was performed using WinQTLCart 2.0 (Basten et al. 1997).

Single Factor (SF)-ANOVA, (MLG)-regression, interval mapping (IM) and composite interval mapping (CIM) were performed. The former three were calculated using SAS program (SAS institute, inc., Cary, NC, 1990), while the QTL map was also drawn using WinQTLCart.

\section{RESULT}

Insect resistance of seeds in parents, $F_{1}, F_{2}$, and $F_{2: 3}$

Seeds of the resistant parent, Jangan mungbean, displayed high resistance to both bruchid and bean bug, while the seeds of susceptible parent, Sunhwa mungbean, were damaged by both. The $F_{1}$ seeds produced between susceptible and resistant parents were completely resistance to both insects. In the reaction of $F_{2}$ seeds to bruchid, chi-square test showed a good fit to a resistance: susceptibility ratio of $3: 1$ $\left(\mathrm{X}^{2}=0.68, \mathrm{P}=0.41\right)$. Inheritance of a single dominant gene conferring bruchid resistance was also confirmed by testing the seeds of $F_{2: 3}$. Of the 27,179 seeds tested, 20,385 displayed resistance, while the remaining 6,794 were damaged (data not shown). These results indicated that resistance to bruchid was controlled by a single dominant gene (Table 2).

However, the segregation mode of $F_{2}$ and $F_{2: 3}$ seeds to bean bug showed a good fit to a 13:3 segregation ratio (data not shown). Cross-reaction test of 123 healthy seeds showing resistance to bruchid revealed 4 seeds damaged by bean bug. Conversely, examination of $134 \mathrm{~F}_{2}$ seeds with resistance to bean bug revealed 10 susceptible to bruchid. Allele test with $F_{2}$ seeds from TC1966 and Jangan mungbean revealed that about $2 \%$ of the $\mathrm{F}_{2}$ seeds showed susceptibility to both bruchid and bean bug (Table 2). These results indicate that the resistance genes to each insect pest have different loci, but are closely linked with each other.

Table 2. Segregation ratio of $F_{1}, F_{2}$, and $F_{2: 3}$ seeds derived from two combinations of crosses with Sunhwa mungbean, Jangan mungbean, and TC1966.

\begin{tabular}{cccccccccc}
\hline & & \multicolumn{2}{c}{$\mathrm{F}_{1}$ seeds } & \multicolumn{2}{c}{$\mathrm{F}_{2}$ seeds } \\
\cline { 3 - 10 } Pest & Crosses & \multirow{2}{*}{$\mathrm{H}^{\mathrm{y})}$} & $\mathrm{D}^{\mathrm{y})}$ & $\mathrm{H}$ & $\mathrm{D}$ & $\chi^{2}$ & $\mathrm{P}$ & \multicolumn{2}{c}{ Cross test } \\
\cline { 3 - 10 } & & & & & & $(3: 1)$ & & $\mathrm{H}$ & $\mathrm{D}$ \\
\hline \multirow{2}{*}{ Bruchid } & $\mathrm{S}^{\mathrm{z})} \times \mathrm{J}^{\mathrm{z})}$ & 14 & 0 & 123 & 35 & 0.68 & 0.41 & 124 & 10 \\
& $\mathrm{~T}^{\mathrm{z})} \times \mathrm{J}$ & 5 & 0 & 960 & 38 & 239.05 & $\mathrm{NS}$ & 950 & 38 \\
\hline \multirow{2}{*}{ Bean bug } & $\mathrm{S} \times \mathrm{J}$ & 14 & 0 & 134 & 36 & 0.65 & 0.25 & 119 & 4 \\
& $\mathrm{~T} \times \mathrm{J}$ & 5 & 0 & 988 & 8 & 311.01 & $\mathrm{NS}$ & 952 & 8 \\
\hline
\end{tabular}

${ }^{2)} \mathrm{S}$ indicates Sunhwa mungbean; $\mathrm{J}$ is for Jangan mungbean; T refers to TC1966.

${ }^{\mathrm{y}} \mathrm{H}$ and $\mathrm{D}$ indicate healthy and damaged phenotypes infested with insect, respectively. 
Marker selection for mapping of the resistance gene

For the construction of a linkage map, three kinds of molecular markers were employed, including SSR, STS, and RAPD markers. Screening for polymorphic markers revealed that only 3 out of 118 SSR markers tested, namely MB14, MB87, and MB91, showed polymorphism in the parents. General primers for the 4 sequences of resistancespecific proteins of mungbean showed polymorphism between parents. After pre-testing of 190 primers for effective RAPD amplification in the parents, 13 RAPD primers were selected for testing in six samples: two bulked samples, two parents and two control checks. In total, 12 RAPD polymorphic bands, including BEXA99, OPB10, OPU06, and OPU11, were successfully cloned and sequenced.
Several sets of primers were also designed and tested for CAP analysis. Digestion with various restriction enzymes revealed that BEXA99 / Mse I , OPB10 / Tsp509, OPU / Mse I , and OPU11 / Mse I generated polymorphic bands between the parents (Fig. 1 and Fig. 2).

\section{Construction of co-dominant linkage map and QTL analysis}

A genetic linkage map with the length of $13.7 \mathrm{cM}$, was successfully constructed using 6 markers: one SSR, one STS, and four CAPs (Fig. 3). Putative QTLs for the resistance to bruchid and bean bug were analyzed according to the susceptibility and survival rate upon exposure to each insect pest. Two QTLs were identified for bruchid resistance,

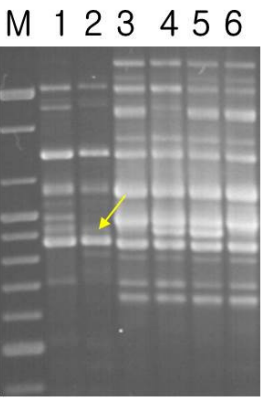

(a)

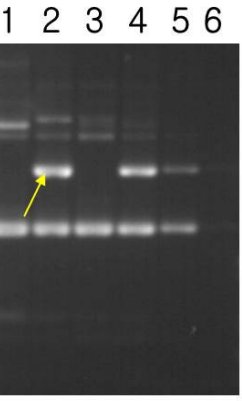

(b)

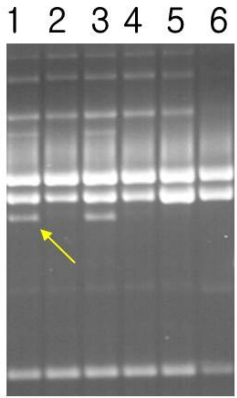

(c)

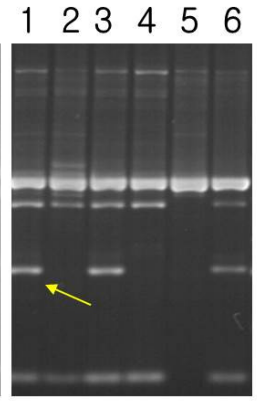

(d)

Fig. 1. Bulked segregant analysis for bruchid and bean bug resistance using random decamers: (a) BEXA99, (b) OPU11, (c) OPB10, (d) OPU06. M: molecular weight marker; Lane 1: Jangan mungbean (resistant parent), Land 2: Sunhwa mungbean (susceptible parent), Lane 3: resistant bulk, Lane 4: susceptible bulk, Lane 5: Keumsung mungbean (susceptible check), Lane 6: TC1966 (resistant check). Arrow indicates polymorphic band between resistant and susceptible bulk.

\section{BEXA99 / Mse I}

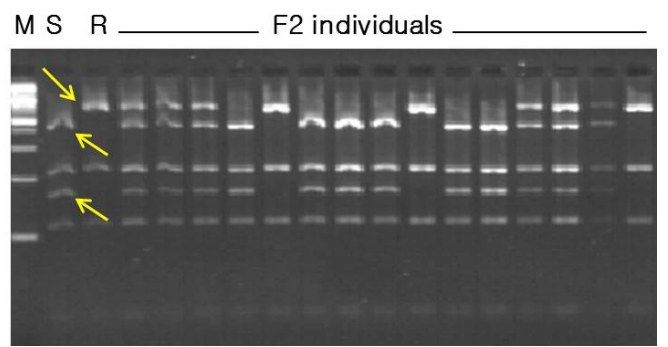

Fig. 2. CAP analysis for bruchid and bean bug resistance genes using BEXA99 for/rev primers followed by Mse I enzyme digestion. Three bands (two from susceptible parent and one from resistant parent) revealed allelic polymorphism between the parents and $F_{2}$ individuals. S: susceptible parent, Sunhwa mungbean; R: resistant parent, Jangan mungbean; M: molecular weight marker. Arrows indicate polymorphic bands for susceptible and resistant parents, respectively. 
while one was detected for bean bug resistance. In addition, one of the QTLs for resistance to bruchid was shared with the QTL for bean bug. The shared QTL for both insects was located in the same region of RP as COPU06 (Fig. 3). The QTLs in the region of MB87-COPU11 and RP-COPU06 explained $45 \%$, and $46 \%$ of the variation in resistance to bruchid, respectively. The QTL for the resistance to bean bug, detected in the region of RP-COPU06, explained 42\% of the variation (Table 3).

\section{DISCUSSION}

Kaga et al. (1998) reported that the resistance of TC1966 to bruchid and bean bug infestation was co-segregated. However, the present study yielded different results. This may be due to the different genetic backgrounds. The present study examined Jangan mungbean, which was developed by backcrossing breeding with the donor parent V2709. Allele test with the $F_{2}$ seeds from TC1966 and

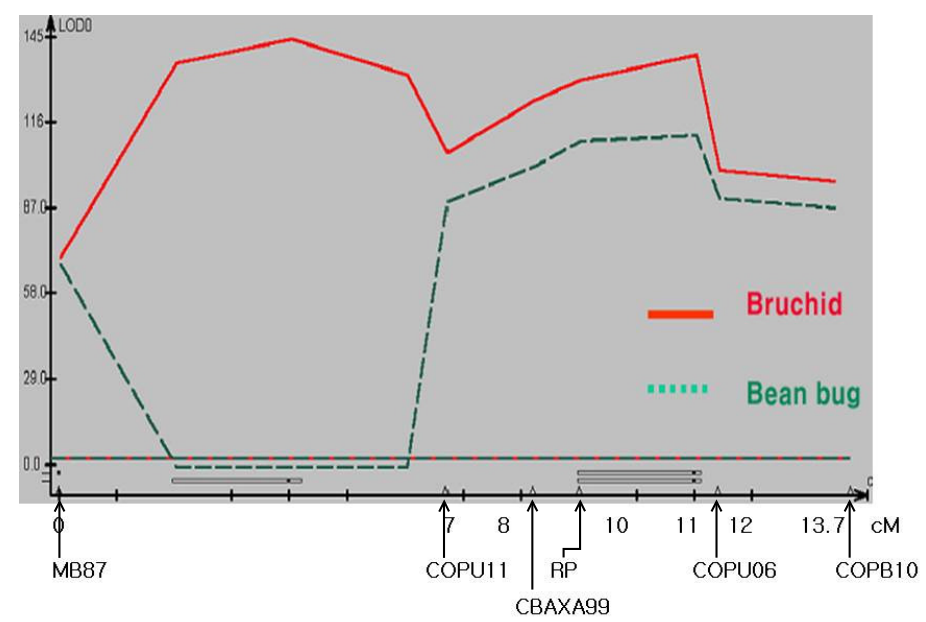

Fig. 3. QTL map for chromosome segment associated with insect resistance using composite interval mapping. Markers are indicated under the $\mathrm{X}$ axis with intervals. Additive effects of each QTL were depicted over the $\mathrm{X}$ axis of the QTL map.

Table 3. QTLs association with resistance to bruchid and bean bug, determined using one-way ANOVA, multiple regression (MLG-Regr.), and composite interval mapping (CIM).

\begin{tabular}{|c|c|c|c|c|c|c|c|c|c|c|c|}
\hline \multirow{3}{*}{ Insect } & \multirow{3}{*}{ Locus } & \multirow{3}{*}{$\begin{array}{c}\text { Map } \\
\text { position } \\
(\mathrm{cM})\end{array}$} & \multicolumn{5}{|c|}{ Single factor ANOVA } & \multicolumn{2}{|c|}{ MLG-Regr. } & \multicolumn{2}{|c|}{ CIM } \\
\hline & & & \multirow{2}{*}{$\mathrm{P}$} & \multirow{2}{*}{$\mathrm{R}^{2}$} & \multicolumn{3}{|c|}{ Allelic means } & \multirow{2}{*}{$P$} & \multirow{2}{*}{$\mathrm{R}^{2}$} & \multirow{2}{*}{ LOD } & \multirow{2}{*}{$\mathrm{R}^{2}$} \\
\hline & & & & & $\mathrm{S}$ & $\mathrm{H}$ & $\mathrm{J}$ & & & & \\
\hline \multirow{6}{*}{ Bruchid } & MB87 & 0 & $5.77 \mathrm{E}-71$ & 0.58 & 76.8 & 27.1 & 4.1 & \multirow{6}{*}{$<.0001$} & \multirow{6}{*}{0.72} & \multirow[t]{4}{*}{77.8} & \multirow[t]{3}{*}{0.45} \\
\hline & COPU11 & 6.7 & 8.03E-98 & 0.69 & 80.7 & 25.6 & 2.4 & & & & \\
\hline & CBAXA99 & 8.2 & $2.02 \mathrm{E}-117$ & 0.76 & 81.8 & 24.4 & 1.4 & & & & \\
\hline & $\mathrm{RP}$ & 9.0 & $7.35 \mathrm{E}-128$ & 0.79 & 81.7 & 23.4 & 1.4 & & & & 0.46 \\
\hline & COPU06 & 11.4 & $1.11 \mathrm{E}-98$ & 0.70 & 80.2 & 26.3 & 2.1 & & & & \\
\hline & COPB10 & 13.7 & $1.50 \mathrm{E}-88$ & 0.66 & 78.8 & 25.7 & 3.3 & & & & \\
\hline \multirow{6}{*}{ Bean bug } & MB87 & 0 & $3.22 \mathrm{E}-68$ & 0.56 & 54.2 & 18.9 & 3.0 & \multirow{6}{*}{$<.0001$} & \multirow{6}{*}{0.67} & \multirow{6}{*}{76.5} & \multirow{6}{*}{0.42} \\
\hline & COPU11 & 6.7 & $5.70 \mathrm{E}-88$ & 0.66 & 56.3 & 18.0 & 2.0 & & & & \\
\hline & CBAXA99 & 8.2 & $1.92 \mathrm{E}-98$ & 0.70 & 56.6 & 17.4 & 1.5 & & & & \\
\hline & $\mathrm{RP}$ & 9.0 & $6.18 \mathrm{E}-108$ & 0.73 & 56.7 & 16.6 & 1.5 & & & & \\
\hline & COPU06 & 11.4 & $1.25 \mathrm{E}-90$ & 0.67 & 56.3 & 18.2 & 1.9 & & & & \\
\hline & COPB10 & 13.7 & $4.74 \mathrm{E}-84$ & 0.64 & 55.7 & 17.6 & 2.9 & & & & \\
\hline
\end{tabular}


Jangan mungbean revealed that about $2 \%$ of the $F_{2}$ seeds showed susceptibility to both bruchid and bean bug (Table 2). This indicates that the resistance genes of Jangan mungbean and TC1966 do not have an allelic relationship with each other. In order to calculate the recombination value of each gene in both genotypes, we attempted to cross test healthy seeds which had already showed resistance to infestation with one of the insects. However, because none of the $F_{2}$ seeds showed susceptibility to both insect pests, the recombination value could not be calculated (data not shown). These results indicate that that the bruchid and bean bug resistance genes of Jangan mungbean and TC1966 have different loci, or are closely linked with each other. This possibility was also reported in other Vigna species. Resistance to $C$. chinensis infestation in black gram (V. mungo (L.) Hepper) appears to be conditioned by a homozygous recessive gene (Fernandez and Talekar 1990), whereas C. maculatus resistance in wild black gram is governed by two duplicated genes (Dongre et al. 1996). Adjadi et al. (1985) reported that two recessive genes govern the resistance to $C$. maculatus in cowpea ( $V$. unguiculata (L.) Walp), while Somta et al. (2006) found three quantitative trait loci (QTLs) associated with resistance to bruchid in rice bean ( $V$. umbellate (Thumb.) Ohwi and Ohashi). Somata et al. (2007) suggested that modifying genes also contributed to the resistance of V2709. Such modifiers were also reported to be involved in bruchid resistance in wild mungbean (Kitamura et al. 1988) and cowpea (Redden et al. 1983).

The genetic localization of a bruchid resistance gene was reported by Kaga et al. (1998) and Chen et al. (2007). Because few molecular markers have been developed up to date, they also used RAPD analysis for the construction of a linkage map. Comparing the previous molecular markers with those presently identified, we successfully incorporated five new molecular markers in a narrow vicinity with the length of $13.7 \mathrm{cM}$. Of the five new molecular markers, three RAPD-based CAPs markers were closely linked to the major QTL, which simultaneously controls resistance to bruchid and bean bug. Another two markers, an SSR named MB87 and an RP derived from resistance-specific protein in mungbean, were newly developed. Moreover, new QTLs conferring resistance to bruchid were found by the composite interval mapping method. These new QTLs were located between MB87 and SOPU11.

Overall, the approaches of inheritance and QTL analysis were found to be very effective for the detection of quantitative trait loci in a narrow vicinity in the chromosome. These results will serve as positional markers for the cloning of interesting genes. Therefore, these newly developed closely linked markers may serve as a facile footprint for finding new resistance genes for bruchid and bean bug in mungbean.

\section{ACKNOWLEDGEMENTS}

This study was supported principally by a grant from the National Institute of Crop Science Research Program (PJ009330), and in part by the Rural Development Administration Research Program (PJ002503), which provided a post-doctoral fellowship.

\section{REFERENCES}

Adjadi O, Singh BB, Singh SR. 1985. Inheritance of bruchid resistance in cowpea. Crop Sci. 25: 740-742.

Dongre TK, Pawer SE, Thakar RG, Harwalker MR. 1996. Identification of resistant sources to cowpea weevil (Callosobrucus maculatus (F.)) in Vigna sp. and inheritance of their resistance in black gram (Vigna mungo var. mungo). J. Stored Food Res. 32(3): 201-204.

Fernandez GCJ, Talekar NS. 1990. Genetics and breeding for bruchid resistance in Asiatic Vigna species. In: Yoshida T (eds) Bruchids and legumes: economics, ecology and coevolution. Kluwer Academic Publishers, Drodrecht, Netherlands, pp.209-217.

Fujii K, Ishimoto M, Kitamura K. 1989. Patterns of resistance to bean weevils (Bruchidae) in Vigna radiata-mungosublobata complex inform the breeding of new resistant varieties. Appl. Ent. Zool. 24(1): 126-132.

Gwag JG, Chung JW, Chung HK, Lee JH, Ma KH, Dixit A, Park YJ, Cho EG, Kim TS, Lee SH. 2006. Characterization of new microsatellite markers in mung bean, Vigna radiata (L.). Mol. Eco. Note. 6(4): 1132-1134.

Ishimoto M, Sato T, Chrispeels MJ, Kitamura K. 1996. 
Bruchid resistance of transgenic azuki bean expressing seed a-amylase inhibitor of common bean. Ento. Exp. et Appl. 79: 309-315.

Kaga A, Ishimoto M. 1998. Genetic localization of a bruchid resistance gene and its relationship to insecticidal cyclopeptide alkaloids, the vignatic acids, in mungbean (Vigna radiata L. Wilczek). Mol. Gen. Genet. 258: 378\&\#8211;84.

Kang CH, Huh HS, Park CG. 2003. Review on true bugs infesting tree fruits, upland crops, and weeds in Korea. Korean Journal of Applied Entomology 42: 269-277.

Kitamura K, Ishimoto M, Sawa M. 1988. Inheritance of resistance to infestation with azuki bean weevil in Vigna sublobata and successful incorporation to $V$. radiata. Jap. J. Breed. 38: 459-464.

Lambrides CJ, Lawn RJ, Godwin ID, Manners J, Imrie BC. 2000. Two genetic linkage maps of mungbean using RFLP and RAPD markers. Aust. J. Agric. Res. 51: 415-425.

Lander ES, Green P, Abrahamson J, Barlow A, Daly MJ, Lincoln SE, Newburg L. 1987. Mapmaker: an interactive computer package for constructing primary genetic linkage map of experimental and natural population. Genetics 1: 174-181.

Michelmore RW, Paran I, Kesseli RV. 1991. Identification of markers linked to disease-resistance genes by bulked segregant analysis: A rapid method to detect markers in specific genomic regions by using segregating populations. Proc. Natl. Acad. Sci. 88: 9828-9832.

Redden RJ, McGuire J. 1983. The genetic evaluation of bruchid resistance in seed of cowpea. Aust. J. Agric. Res. 34: 707-715.

Rozen S, Skaletsky HJ. 2000. Primer3 on the WWW for general users and for biologist programmers. In: Krawetz S, Misener S (eds) Bioinformatics methods and protocols: Methods in Molecular Biology. Humana Press, Totowa, NJ, pp.365-386.

Somta P, Ammaranan C, Peter ACO, Srinives P. 2007. Inheritance of seed resistance to bruchids in cultivated mungbean (Vigna radiata L. Wilczek). Euphytica 155: 47-55.

Yang TJ. 1994. Application of RFLP analysis in the breeding of mungbean [Vigina radiata (L.) Wilczek] for Bruchidresistance. Master's thesis, Seoul National University, Korea.

Young ND, Kumar L, Menancio-Hantea D, Danesh D, Talekr NS, Shammugasundarum S, Kim DH. 1992. RFLP mapping of a major bruchid resistance gene in mungbean (Vigna radiata L. Wilczek). Theor. Appl. Genet. 84: 839-844. 